\title{
Inventory and monitoring of historical cultural heritage buildings on a territorial scale: a preliminary study of structural health monitoring based on the CARTIS approach
}

\author{
Renato S. Olivito ${ }^{1}$, Saverio Porzio ${ }^{1}$, Carmelo Scuro ${ }^{2}$, Domenico L. Carnì ${ }^{3}$, Francesco Lamonaca ${ }^{4}$ \\ ${ }^{1}$ DINCI - Department of Civil Engineering, University of Calabria, 87036 Rende (CS), Italy \\ 2 Department of Physics, University of Calabria, 87036 Rende (CS), Italy \\ ${ }^{3}$ DIMES - Department of Informatics Modelling Electronics and Systems Science, University of Calabria, 87036 Rende (CS), Italy \\ ${ }^{4}$ DING - Department of Engineering, University of Sannio, 82100 Benevento, Italy
}

\begin{abstract}
Earthquakes induce dynamic stresses in structures, and past seismic events have demonstrated that existing heritage buildings are highly vulnerable. This vulnerability applies to both reinforced-concrete and masonry buildings, which are concentrated in historic centres throughout Italy. Significant variations in construction account for the inadequacy of existing structures to withstand seismic actions, such as the materials used and the construction details, which can be neglected in building practices. This work focuses on the analysis of heritage buildings through an inventory using the Caratterizzazione TIpologica Strutturale (CARTIS) form developed by the Seismic Engineering University Laboratories Network in conjunction with the Civil Protection Department. On knowing a building framework, structural health monitoring (SHM) systems can be applied on the town compartments (TCs) that are prone to the highest vulnerabilities. A priority criticalities scale can be devised starting from the building inventory by identifying the TCs through the CARTIS-based data. This approach can be used to determine a safety threshold obtained via structural parametrical analysis using commercial software (VEMnl) with different building typologies. The next stage consists of the implementation of appropriate SHM to provide important information regarding the structural integrity of the buildings. The proposed methodology is outlined in this paper with reference to the suggested SHM system.
\end{abstract}

\section{Section: RESEARCH PAPER}

Keywords: seismic vulnerability; Monitoring System; Structural Health Monitoring (SHM); IoT

Citation: Renato Sante Olivito, Saverio Porzio, Carmelo Scuro, Domenico Luca Carnì, Francesco Lamonaca, Inventory and monitoring of historical cultural heritage buildings at the territorial scale. A preliminary study of SHM based on CARTIS approach, Acta IMEKO, vol. 10, no. 1, article 9, March 2021, identifier: IMEKO-ACTA-10 (2021)-01-09

Editor: Eulalia Balestrieri, University of Sannio, Italy

Received April 22, 2020; In final form June 18, 2020; Published March 2021

Copyright: This is an open-access article distributed under the terms of the Creative Commons Attribution 3.0 License, which permits unrestricted use, distribution, and reproduction in any medium, provided the original author and source are credited.

Corresponding author: Carmelo Scuro, e-mail: carmelo.scuro@unical.it

\section{INTRODUCTION}

Seismic-damage prevention is one of the main goals of researchers in the management of historical heritage buildings. However, an appropriate appraisal of the building's heritage requires the definition of the building's characteristics for examination, especially in terms of (i) the construction type (i.e. reinforced concrete $[\mathrm{RC}]$ or masonry), (ii) the intended use (i.e. residential or specialised), and (iii) the state of conservation (i.e. good or neglected) [1]-[3].

The first step in obtaining a building inventory is to ensure the survey measure is focused on non-specialist buildings. The narrowing of the investigation framework is important for optimising the analytical effectiveness 0, [5]. This paper presents a preliminary study aimed at defining a methodology for coupling the recent trends in building inventory procedures with those of structural monitoring. In the last few decades, various attempts have been made to formulate refined collecting models. At the regional scale, the census data provides the main source for a classification of building vulnerability. Meanwhile, the data sources provided by interview-based or building-by-building surveys allows for an in-depth examination, despite the significant difficulty in accessing the relevant information [6]. From the collaboration between the Seismic Engineering University Laboratories Network (ReLUIS) and the Civil 
Protection Department (DPC) emerged the Caratterizzazione TIpologica Strutturale (CARTIS) tool. This is a territorial knowledge tool based on the concept of buildings with specific structural feature typologies and presents an approach that is remarkably adaptable to the diversity of buildings throughout Italy, where each city is the result of an historic evolution leading to the current situation.

The use of speedy and efficient approaches allows for the individuation of the critical town compartments (TCs) that indicate the major structural safety issues. Real-time damage identification systems can help to mitigate seismic risk. Here, the aim is to act exclusively on the most vulnerable buildings with minimal intervention in order to optimise both the technical and the economic resources, which can be achieved by using structural health monitoring (SHM) systems combined with the internet of things (IoT) paradigm [7]-[14].

This work presents a preliminary study aimed at defining an integrated methodology for inventory, monitoring, transmission, and data management. The remainder of the paper is organised as follows. Sections 2-4 outline the CARTIS approach and the theoretical formulation of seismic vulnerability as well as the equivalent frame model. Section 5 then introduces and explains the monitoring systems related to historical building construction before section 6 presents the preliminary study based on the application of CARTIS, with the parametric numerical modelling and the SHM system presented. The conclusions are then drawn in section 7 .

\section{BUILDING INVENTORY USING THE CARTIS APPROACH}

Defining homogeneous territorial zones, namely, the TCs, is the first step of the CARTIS methodology [15]. These zones group buildings of the same age and construction technique. The data collection is carried out by filling out forms subdivided into different levels: a first-level single form for the city (Figure 1); second-level forms, one for each TC individuated in the local territory (Figure 2); and third-level forms, one for each building type (BT) within each TC (Figure 3).

Figures 1, 2 and 3 show the application of the various levels of CARTIS to a small town located in the central part of the Calabria Region, Fuscaldo, identifying two different TCs in its historical compartment and the most ubiquitous masonry building types.

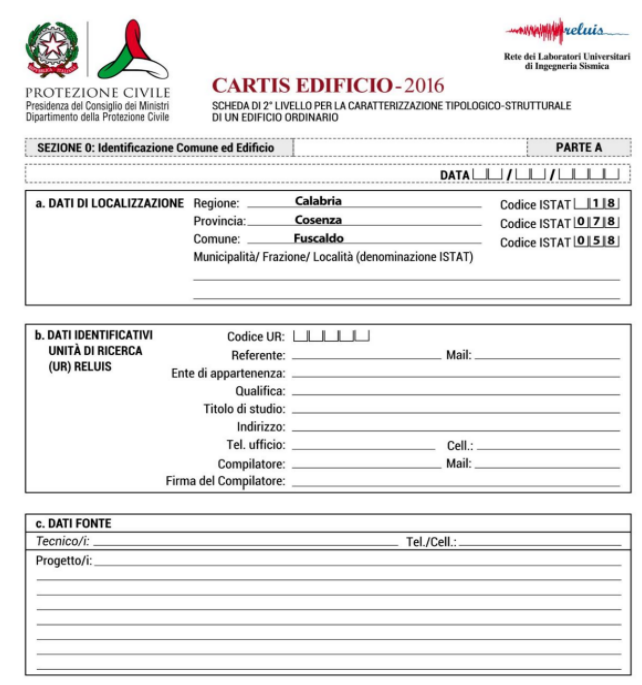

Figure 1. First-level CARTIS approach.

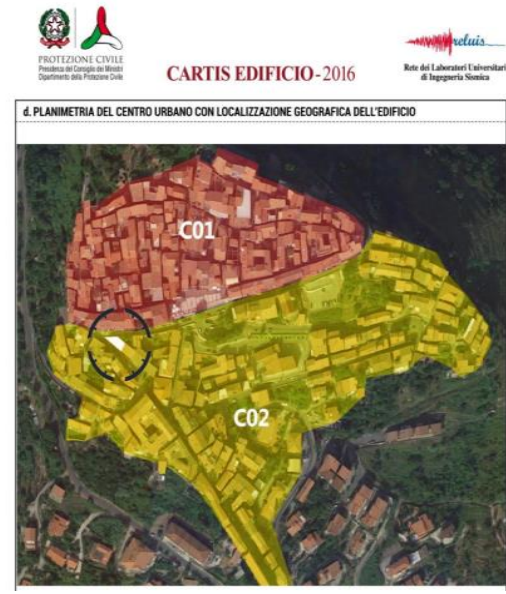

Figure 2. Second-level CARTIS approach. Identification of TCs.

Qualified technicians (professionals and researchers) conduct the survey campaign both in terms of building-by-building surveys and through interviewing local experts operating in the sector with an in-depth knowledge of the territory.

In third-level surveying, the classification of the building typologies of each compartment is carried out by identifying the macro-classes of the buildings, that is, RC or masonry (labelled as CAR and MUR, respectively, on the forms). Other determining factors that contribute to defining the typologies include slab-type, the number of floors, and the number (percentage) of openings. However, it is worth noting that there can be multiple masonry typologies. In RC buildings, the appropriate building details correspond to the date of construction (e.g. class of concrete strength, diameter/spacing of strips, percentage of rebars in the beams and pillars). Meanwhile, for masonry buildings, a more marked variability tends to exist with the same type of material due to the texture and the cross sections, the presence of courses and diatons, and the type of corner connection and thin-bed joint, etc. [16], [17]. Furthermore, these buildings are generally geometrically irregular in terms of both plan and elevation. Clearly, the role of the data collector is fundamental and is highly related to their ability to access information.

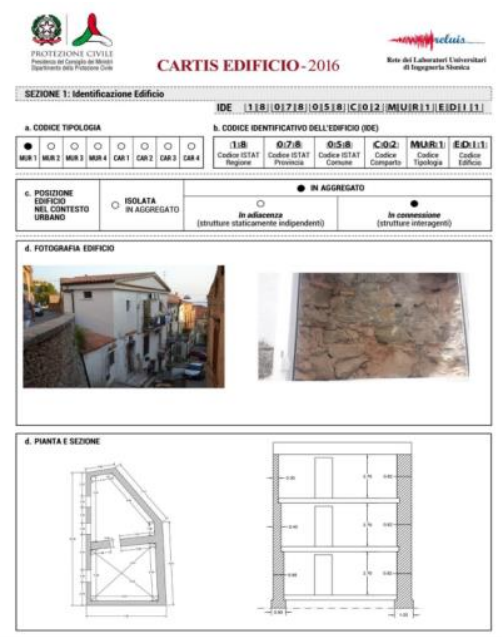

Figure 3. Third-level CARTIS approach. Identification of the characteristics of the existing buildings in the various TCs. 
While the collected data may appear to be accumulated, they can still be used to define vulnerability models on different scales. Another aspect of the potential of CARTIS is the web application (available at https://cartis.plinivs.it), where all the data manually gathered through the forms are introduced and are accessible to the scientific community. The web application guides the data entry procedure, reducing the chances of human error that can affect the collection. Moreover, specific 'query' commands allow the data to be queried. As such, the same information can be subjectively assessed to define and calibrate new refined models of seismic vulnerability [17], [18].

\section{SEISMIC VULNERABILITY}

Nowadays, various approaches are employed to estimate the seismic vulnerability of buildings [19]. However, the strategy employed must establish a priori (i) the differentials that contribute to defining the seismic reactions of a typological class, (ii) the damage scale, and (iii) the extent to which these classified buildings are vulnerable to a determined level of seismic intensity [20]. Therefore, researchers have attempted to standardise the vulnerability concept to ensure analogous investigations [21].

In this framework, the damage probability matrix (DPM) is one of the main tools employed [22]. This relates to the probability that a determined damage level $k$ occurs for a seismic event of a certain intensity,

$$
I: p_{k \mid I}=P[D=k \mid I]
$$

taking into account a specified building class. For each $I$ value, which represents the vulnerability index of each building, the distribution of damage $d$ presents a mean value of

$$
d(I)=\frac{1}{5} \sum_{k=0}^{5}\left(p_{k \mid I} \cdot k\right)
$$

where the term $1 / 5$ is related to the five damage degrees $(D k)$ foreseen by this type of approach. According to the adopted model, specific curves known as vulnerability curves (Figure 4), which plot the damage distribution $d$ vs. intensity $I$, can be drawn.

When several damage grades of $D k$ are taken into account, the curves become fragility curves (Figure 5), which are regularly developed on the basis of a lognormal distribution of $d$ values [23].

Seismic fragility is identified in terms of the chance that the seismic capacity related to a ground-motion parameter (peak ground acceleration [PGA]) $A$ of a structure is below a threshold $a$ of that PGA [24], [25].

$$
p_{F}(a)=P\{A<a \mid P G A=a\}
$$

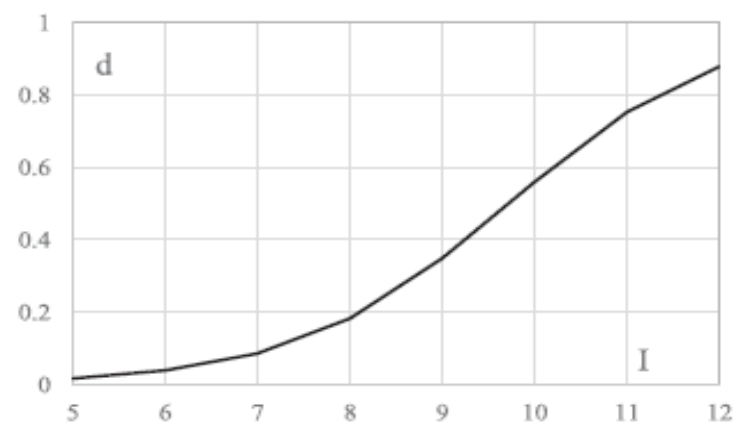

Figure 4. Example of a vulnerability curve.

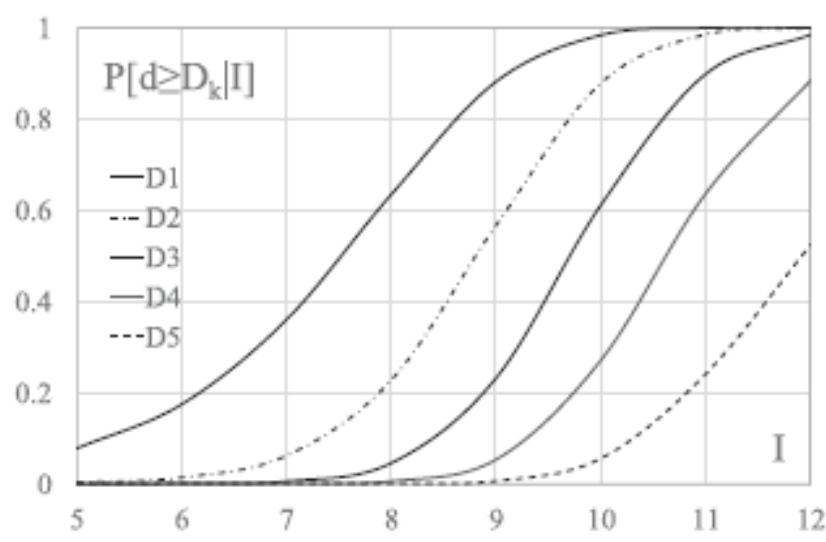

Figure 5. Example of a fragility curve.

The PGA seismic capacity $A$ of a structure is often expressed as a function of three variables:

$A=A_{m} \varepsilon_{U} \varepsilon_{R}$

where $A_{m}$ is the median PGA seismic capacity, $\varepsilon_{U}$ is the epistemic uncertainty of $A$ due to a lack of knowledge and is a random variable representing uncertainty, and $\varepsilon_{R}$ is linked to the concept of aleatory uncertainty and is a random variable representing the inherent randomness of $A$ [26]. The two random variables are taken to be lognormally distributed with unit average values and with logarithmic standard deviations of $\beta_{U}$ and $\beta_{R}$, respectively [27]. In accordance with Eq. 4 and the assumption that $\varepsilon_{R}$ and $\varepsilon U$ are lognormally distributed, the seismic fragility curve, which identifies the probability of failure given a $P G A$ threshold $a$ at a confidence level of $Q=q$, is expressed as follows in accordance with [28]:

$$
\begin{aligned}
& p_{F}(\mathrm{a}, \mathrm{q})=\mathrm{P}\{A<a \mid P G A=a, Q=q\}= \\
& =\Phi\left[\frac{\ln \left(\frac{a}{A_{m}}\right)+\beta_{U} \Phi^{-1}(q)}{\beta_{\mathrm{R}}}\right]
\end{aligned}
$$

where $\Phi$ represents the standard normal distribution function. The confidence levels $Q$ are often taken as various discrete values, such as $5 \%, 50 \%$, or $95 \%$. Generally, this equation identifies a family of seismic fragility curves for various levels of confidence, as shown in Figure 6 [29].

It is possible to obtain a high confidence of low probability of failure (HCLPF) seismic capacity in terms of a selected PGA by solving Eq. 5 with a $5 \%$ probability of failure and a $95 \%$ confidence level. The subsequent analysis will lead to the formulation of Eq. 6:

$C_{H C L P F}=A_{m} \mathrm{e}^{-1.65\left(\beta_{R}+\beta_{U}\right)}$

Here, the median capacity $\boldsymbol{A m}$, as well as the associated randomness $\beta_{\mathrm{R}}$ and uncertainty $\beta_{U}$, become the principal values to calculate to obtain the seismic fragility curves and the HCLPF seismic capacity of a given structure [30].

The safety factor, $F$, which is an intermediate random variable, is used to calculate the $A m, \beta_{\mathrm{R}}$, and $\beta_{U}$. Here, $F$ describes the extent to which the PGA seismic capacity $A$ is above the reference earthquake level in terms of the same $P G A$ quantity ARef and is defined as follows: 


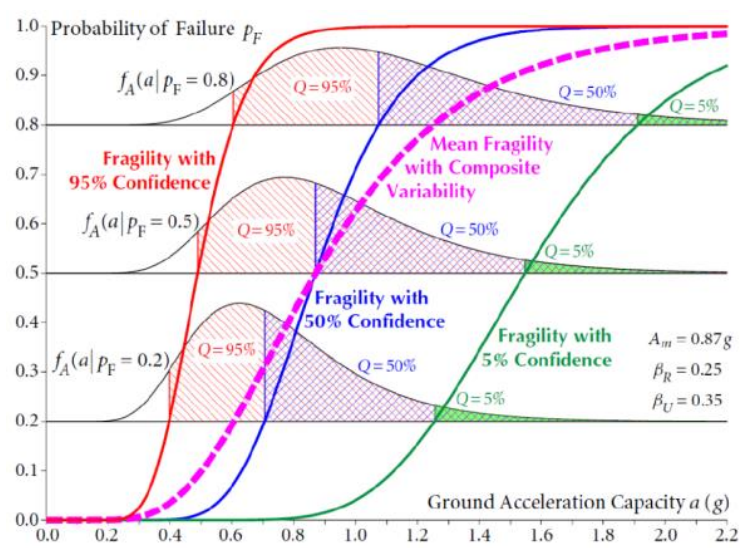

Figure 6. Fragility curve based on the formulation proposed using Eq. 5 [29].

$$
A=F \cdot A_{\operatorname{Re} f}
$$

Meanwhile, the physical meaning of $F$ is the ratio of actual seismic capacity of the structure analysed to the actual response (demand) of the same in terms of the reference earthquake chosen for the analysis.

It is clear that the vulnerability studies carried out using these approaches lead to a comprehensive overview of the most critical building classes. Generally, higher mean damage is experienced by the more vulnerable building classes than by the less vulnerable classes. Attention should be paid to these buildings when setting up systems for monitoring the structural safety in real time.

However, past earthquake data have revealed that a given building class may perform better in the case of weaker seismic events than in the case of stronger events. Thus, it could prove difficult to compare different building classes in terms of vulnerability.

\section{THEORETICAL FORMULATION OF EQUIVALENT FRAME MODEL}

The seismic analysis of masonry structures is conducted using software based on equivalent frame or macro-element models [31], [32]. In these approaches, the walls are subdivided into the vertical elements - the piers - and the horizontal elements - the spandrels interconnected by rigid nodes [33], [34]. As such, the structural response is brought back to the constitutive laws of these elements.

Generally speaking, in modelling and analysis techniques, the contribution of the spandrels is neglected and, even at the regulatory level, their effectiveness is often subordinated to the presence of tie-rods or RC bond-beams. Thus, in assessing the safety of existing buildings, this approach leads to a large number of them being labelled as 'unsafe'. It is clear that this outcome is not plausible, and that the hypothesis adopted is too burdensome since the possible contribution of the spandrels is not considered [35], [36].

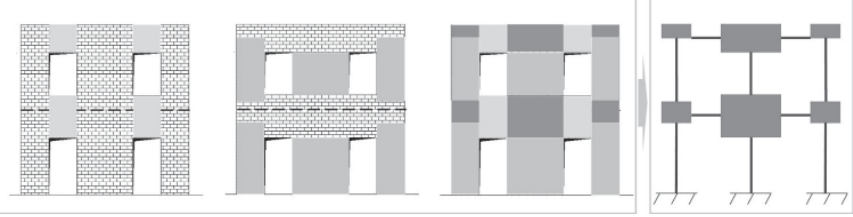

Figure 7. Equivalent frame idealisation [35].

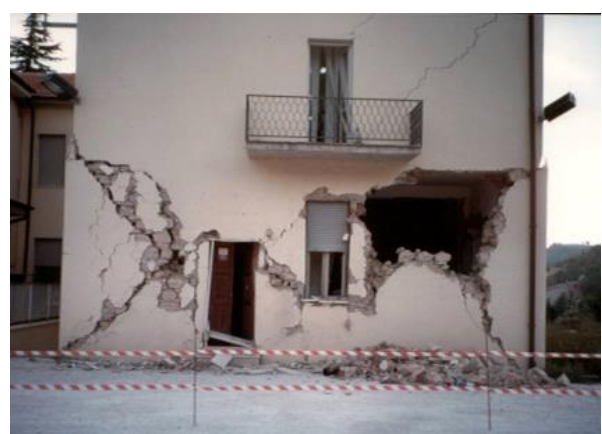

Figure 8. Damage that occurs in piers during a seismic event.

Certain modelling strategies for masonry structures are based on the identification of the macroscopic structural elements. These are defined in terms of finite elements (FEs) - membranes [37]-[39] or frame solids [40], [41] - from a geometric and kinematic point of view, or in terms of generalised internal forces from a static point of view [34]. The latter models are aimed at a substantial reduction of the computational burden, as they are based on a discrete modelling in which the basic element is designed to model a given masonry panel. According to a more simplified approach, the basic macro-elements can represent complete piers and/or spandrels. This reduces the computational burden and decreases the degrees of freedom (DOF) of the structural system.

The so-called frame models are the most commonly used macro-models and are based on a discretisation of the walls using the macro-elements. Here, the walls are regarded in terms of an idealised frame, in which rigid nodes connect the deformable elements (Figure 7) [35]. Meanwhile, the piers are the elements that discharge the loads to the ground, and their failure causes the collapse of the wall, while, in contrast, the spandrels - which are vertically aligned with the openings - influence the behaviour of the wall in relation to the degree of coupling with the piers without directly causing the collapse.

This idealisation derives from the observation of the damage caused by an earthquake in relation to the concentration of diagonal cracks in these elements and the absence of cracking or damage mechanisms in the rigid nodes (Figure 8). In fact, it is assumed that in the rigid nodes, the strains remain in the elastic field, which can result in their contribution being neglected in the evaluation of the seismic behaviour of the building [42], [43].

In the new Italian Technical Standard (NTC 2018), the spandrels are considered as $90^{\circ}$ rotated piers. However, due to the anisotropy of the material, the behaviour between the piers and the spandrels will be different, depending on whether the direction of the applied forces is orthogonal (piers) or parallel (spandrels) to the layout of the mortar bedding joints.

The Italian NTC 2018 assigns a resistance to damage value for the spandrels only in the presence of tensile-strength elements capable of generating a compressive stress. The bending strength of these structural elements tends to be related to the formation of the diagonal strut mechanism that guarantees the coupling with the piers. However, even in the absence of additional elements, the masonry will tend to have a considerable resistance to bending stress due to the friction force between the blocks, especially with spandrels characterised by small dimensions.

To obtain moderate values of the axial load acting on the spandrels and the related buckling strength, Eq. 8 was employed following modification of the formulation used for the piers (Eq. 7): 
$M_{u}=\frac{N \cdot t \cdot b^{2}}{2 A}\left(1-\frac{N}{b \cdot t \cdot k \cdot f d}\right)$

$M_{u}=\frac{\sigma_{0} \cdot t \cdot b^{2}}{2}\left(1-\frac{\sigma_{0}}{k \cdot f h d}\right)$

$\sigma_{0}=\frac{P}{t \cdot b}$

where $N$ is the compression load applied to the piers, $t$ is the thickness of the masonry element, $b$ and $b$ are the base and the height, respectively, of the pier or spandrel, $A$ is the cross section of the element and is equal to $h \cdot t, f_{d}$ is the design compressive strength of the masonry, $f_{b d}$ is the design horizontal compressive strength of the masonry, $P$ is the compressive horizontal load applied to the spandrel, and $k$ is an imposed coefficient less than or equal to 0.85 .

In the case of the presence of tie-rods or RC bond-beams in the structure, the value of the buckling is calculated using Eq. 9:

$$
M_{u}=\frac{H_{p} \cdot h}{2}\left(1-\frac{H_{p}}{0.85 \cdot \mathrm{fhd} \cdot \mathrm{h} \cdot t}\right)
$$

where $H_{p}$ is the minimum value of the tensile stress between reinforcement element (tie-rod or RC bond-beam) and $0.4 b \cdot t f_{b d}$.

The strength and stiffness of the piers and spandrels are determined by the relative failure criteria, while the node element is considered infinitely rigid and resistant.

The great advantage of this method lies in the possibility of reproducing the non-linear behaviour of the wall panels. The piers and the spandrels are modelled through two-dimensional finite macro-elements that are representative of wall panels, with two nodes and three DOF per node $(u x, u z$ roty).

The remaining wall portions are therefore considered as rigid nodes, as identified in the wall plane by two points $(\mathrm{x}, \mathrm{z})$, to which the macro-elements are connected, with the latter transmitting the forces to each node along the three DOF. This approach requires a limited number of DOF with a reasonable computational burden, allowing for the analysis of complex models of unrestored masonry structures obtained by assembling the walls and horizontal elements.

In this approach, the loads are only applied to the nodes, meaning the element is not loaded along its own axis. In the constitutive laws, the initial elastic branch is directly determined by the shear and the bending stiffness, calculated on the basis of the geometric and mechanical properties of the masonry wall, as summarised in the stiffness matrix $K e$ [29], [38]:

$$
K_{e}=\left[\begin{array}{cccccc}
\frac{12 E J \eta}{b^{3}(1+\psi)} & 0 & -\frac{6 E J \eta}{h^{2}(1+\psi)} & -\frac{12 E J \eta}{b^{3}(1+\psi)} & 0 & -\frac{6 E J \eta}{b^{2}(1+\psi)} \\
0 & \frac{E A}{b} & 0 & 0 & -\frac{E A}{b} & 0 \\
-\frac{6 E J \eta}{b^{2}(1+\psi)} & 0 & \frac{E J \eta(4+\psi)}{b(1+\psi)} & \frac{6 E J \eta}{b^{2}(1+\psi)} & 0 & \frac{E J \eta(2-\psi)}{b(1+\psi)} \\
-\frac{12 E J \eta}{b^{3}(1+\psi)} & 0 & \frac{6 E J \eta}{b^{2}(1+\psi)} & \frac{12 E J \eta}{b^{3}(1+\psi)} & 0 & \frac{6 E J \eta}{b^{2}(1+\psi)} \\
0 & \frac{E A}{b} & 0 & 0 & -\frac{E A}{b} & 0 \\
-\frac{6 E J \eta}{h^{2}(1+\psi)} & 0 & \frac{E J \eta(4+\psi)}{b(1+\psi)} & \frac{6 E J \eta}{b^{2}(1+\psi)} & 0 & \frac{E J \eta(4+\psi)}{b(1+\psi)}
\end{array}\right]
$$

where $\psi$ is the coefficient calculated as $1.2 \cdot E / 2 /\left(G h^{2}\right), E$ and $G$ are the elastic and shear modulus, respectively, $A$ and $J$ are the cross-section area and the moment of inertia of the panel, respectively, $l$ and $b$ are the length and height of the panel, respectively, and $\eta$ is the stiffness reduction coefficient [44], [45].

The employment of the equivalent frame model for the analysis of masonry structures allows for the identification of the possibility of schematising as well as buildings with onedimensional elements. To calculate the stresses, it is simply necessary to solve the structural scheme of the frame (as is performed, for example, for RC structures).

Since masonry walls are configured as two-dimensional elements, in which two dimensions (width and length) are preponderant compared to the third (thickness), the simplifications of the Bernoulli model cannot be applied. In fact, this model is applied to the beam elements, i.e. a one-dimensional element for which two dimensions are negligible with respect to the longitudinal development.

The stiffness of the elements is schematised according to Timoshenko's theory, which takes into account the bending and shear component of the strain [45]:

$$
K=\frac{1}{\left(\frac{b^{3}}{12 E I}\right)+\left(\frac{1.2 \cdot b}{G A}\right)}
$$

The behaviour of the spandrels strongly influences the overall response. In fact, in the case of tensile-strength elements, the coupling between the piers is ensured while the rotational behaviour of the piers occurs in the absence of tensile-strength elements [46], [47].

\section{MONITORING SYSTEM FOR HISTORICAL BUILDINGS}

Through the application of the CARTIS approach, an historic city centre can be classified, ensuring the individuation of the building compartments that could be most damaged when subjected to seismic action. Given this, monitoring these compartments through the application of preventive SHM systems becomes an interesting pursuit.

Here, the modification of structural behaviour associated with the local dissimilarities in structural rigidity, which are generally the result of seismic events or dynamic loads, is achieved through monitoring the dynamic actions and assessing the dynamic parameters [48].

Vibration-based SHM systems are highly attractive since they can provide reliable dynamic parameter estimates from in-service response data. Generally, automated operational modal analysis (OMA) techniques incorporating a small number of sensors provide these results [49]-[51].

Forecasting the degradation of the physical and chemical properties of the masonry - the main raw material used in historic buildings - is affected by the sensitivity of the SHM sensor [52], [53].

In the near future, the new technologies will attempt to resolve the aforementioned problem by adopting the simulation of intelligent data processing by associating SHMs with the IoT paradigm [54], [55]. At present, the events that cause great damage to the engineering structures are studied through the transformation of models that simulate their behaviour. This is because the attendant processes are often dynamic and tend to change over time. If the dynamics of the source events are greater than those in the real world, their description will prove to be difficult [56]. 


\section{PRELIMINARY STUDY}

The CARTIS methodology was set up in relation to a case study to define a preliminary research. Here, the main objective was to implement an SHM system to be used on the most vulnerable building classes, individuated using the CARTIS approach. The methodology is viable only for residential buildings, those that are the most ubiquitous throughout the region and that have possessed the same properties over time. Specialised buildings, such as aristocratic palaces, religious buildings, and other historic buildings, require specific acumen developed using alternative methodologies [59]-[62]. This work aims to assess the subjection to seismic risk of an urban centre in the Calabria region, southern Italy, namely, Mendicino. Specifically, the study area is the 'old town', which is widely held to be the most vulnerable TC of the town. After analysing the building inventory and thereby identifying the TC through the CARTIS-based data, a study based on the pushover approach [63] applied to the most common BTs of the TC was carried out. The seismic safety indexes of the patterns identified were elaborated by varying the geometric and structural parameters [36] using VEMnl calculation software. As such, a qualitative interpretation of the urban fabric was carried out, supplying a classification of the most suitable strengthening for each BT configuration.

With regard to the monitoring system, a possible preliminary SHM system for observing the building sectors in real time is proposed in this paper, which consists of a cyber part and a physical part. Within this context, the quality of analytical or numerical models, the adoption of a specific algorithm and the attendant parameters, and the accuracy of the sensor measurements are all potential sources of error and uncertainty [64].

\subsection{CARTIS-based methodology for a case study}

The case study in question relates to the municipality of Mendicino, which is in close proximity to the provincial capital of Cosenza. While the territory under investigation is extensive (35.7 $\left.\mathrm{km}^{2}\right)$, the built-up area includes the 'old town' and 'expansion area' TCs (Figure 9), while further subdivisions into smaller TCs are possible. However, this work is aimed at individuating a prevalent BT within the old town (Figure 10) so as to carry out relevant studies on the seismic susceptibility of these buildings and the possible reinforcement measures. Thus, the focus is on the second and third levels of the CARTIS forms.

The old town TC was the only compartment in the area until 1954. Masonry BTs are the principal type in this TC and are

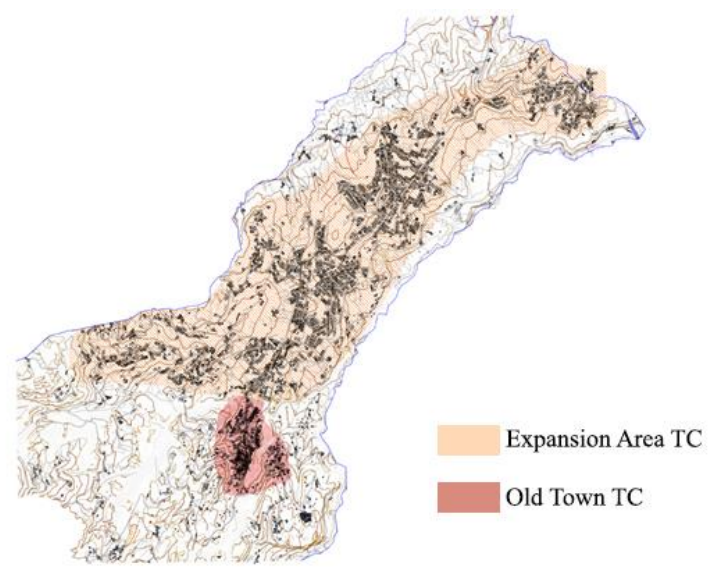

Figure 9. The TCs of the municipality of Mendicino.

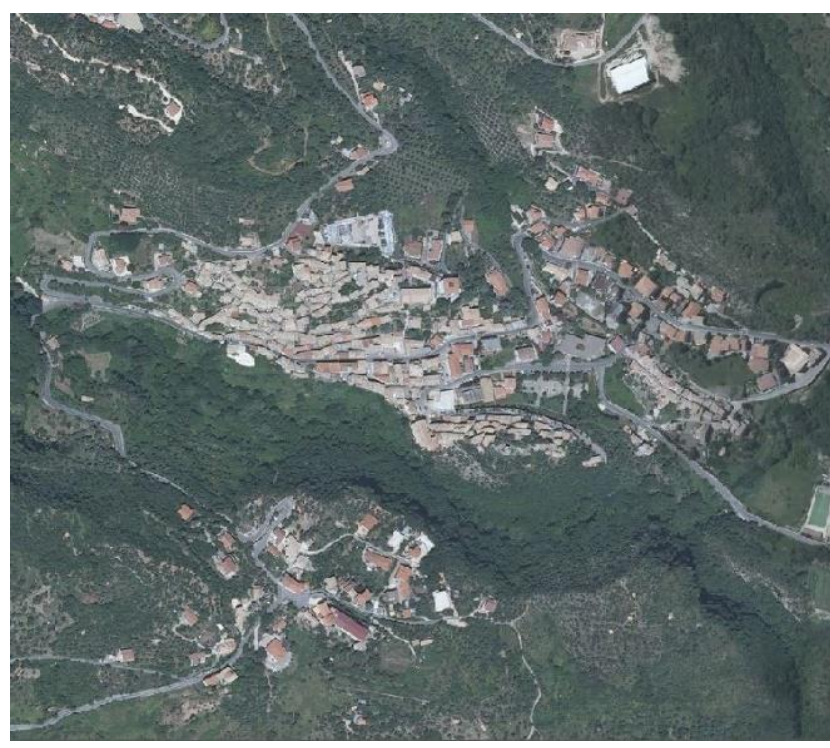

Figure 10. Old town TC.

classified in terms of three types according to the formal and construction properties. Nonetheless, there are examples of RC buildings that were not taken into account during the survey campaign performed with the aid of the second-level forms. In typological terms, the terraced house is the most ubiquitous BT in the area, formed by the primary unit known as a 'tower-house', as illustrated in Figure 11.

For the definition of the structural behaviour of the BTs, three actual buildings (square plan, rectangular plan, and irregular plan) located at three different points of the old town TC were considered. In brief, the most common properties of the towerhouse covering all typologies are as follows:

- an average storey height of $2.50 \mathrm{~m}$;

- two- to three-storey structures with elevations mainly built in the mid-twentieth century;

- a ground floor, largely semi-underground, with a height lower than that of the intermediate levels. The intended use has changed from a workshop or a shelter for animals to a residential area;

- $\quad$ a top floor with a further reduction in height (in $\mathrm{m}$ );

- wide openings compared with the size of the masonry panels.

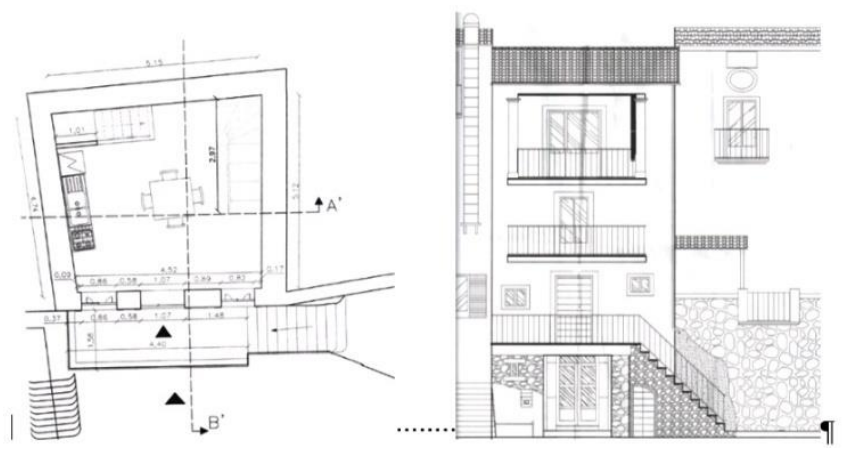

Figure 11. Typological example of the tower-houses in Mendicino. 
Other applicable parameters, in addition to the shape of the plan, are as follows:

- the thickness of the masonry $(=0.60 \mathrm{~m})$ throughout the entire height;

- the masonry type, from the weaker rubble masonry to the stronger masonry blocks;

- the different ground floor heights, ranging from $2.30 \mathrm{~m}$ to $2.80 \mathrm{~m}$;

- the type of slab: wooden slab (lightweight) or steel I-beam with hollow flat blocks (stiffer).

According to the pushover approach established by the Italian Structural Codes [65], [66], the seismic safety of a building is defined by the following:

$$
i_{s}=\frac{u_{\max }}{d_{\max }}
$$

This index represents the ratio of capacity displacements identified in the control point $\left(u_{\max }\right.$, generally situated on the centroid of the attic floor) to seismic demand $\left(d_{\max }\right)$. In this paper, the aim is to identify the safety indexes by varying the percentage of openings (from $9 \%$ to $20 \%$ ) and the mechanical parameters of the structure. Here, $<1$ is the non-reliability condition.

\subsection{Parametric analysis}

Parametric seismic analysis was carried out using the VEMnl software based on the schematisation of buildings using the equivalent frame method. The structures considered are all the tower-house type and differ in terms of plan (square, rectangular, and irregular). In addition, typological evolutions were identified for each typology based on the number of storeys, which ranged from two to three. Table 1 and Figure 12 show the evolution of the basic elements and the eight variants analysed, which were distinguished according to ground floor height $h_{p t}$, the raw material (rubble stone or ashlars), and the type of slab (wood or rigid). The thickness of the masonry was set at a constant $0.60 \mathrm{~m}$.

Analyses were conducted for each type of plan, for each of the eight variants, for all two-storey buildings and, subsequently, for all three-storey buildings by varying the percentage of openings in the structure.

The ultimate aim was to identify the safety index $(I s)$ for each individual variant of the model. For masonry buildings, the analysis using NTC 2018 must be conducted for 16 seismic load configurations, eight along the $x$ axis and eight along the $y$ axis,
Table 1. Characteristics of the eight models.

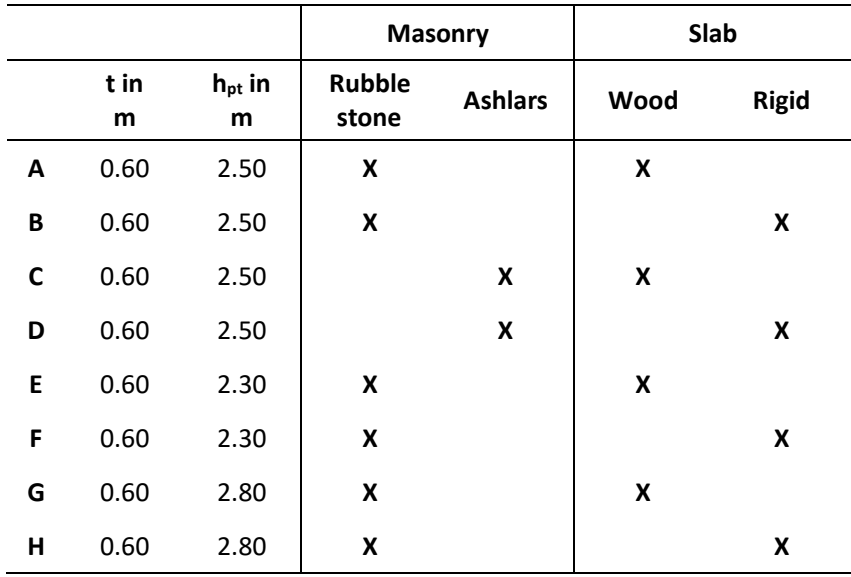

proportional to the masses and heights, and another eight with consideration of a possible rotation of the action along the two main axes.

For simplicity, only the values obtained for the configuration of the seismic analysis proportional to the masses along the positive $x$ direction are reported.

The numerical analysis led to the identification of 72 safety indices, for each typology of seismic load combination, calculated for the eight configurations of the two-storey square plan by varying the percentage of openings in the wall in a range of approximately $10 \%-20 \%$. This was subsequently performed for each type and for each load combination. The results of the first load combination are presented in Table 2 and Figure 13. Similar results are obtained for: three storey square plane, two storey rectangular plane, three storey rectangular plane, two storey irregular plane and three storey irregular plane. The results are presented in the Table 3 - Table 7 and Figure 14-Figure 18, respectively
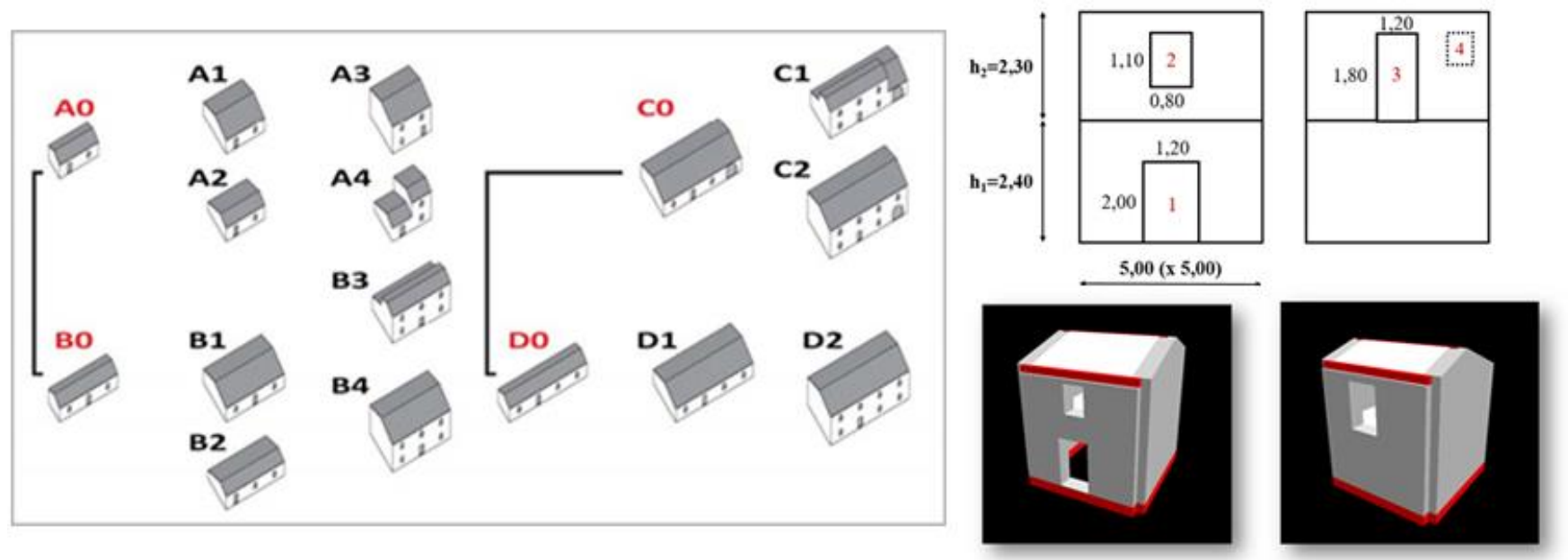

Figure 12. The parametric analysis was carried out starting from elementary cells AO and B0, which together identified the different BTs present in the Mendicino area. The figure also shows a scheme of the square-shaped BT elevations and the attendant model in the VEMnl software. 
Table 2. Safety index values for two-storey square plan.

\begin{tabular}{ccccccccc}
\hline \% & A & B & C & D & E & F & G & H \\
\hline $\mathbf{1 0 . 0}$ & 3.38 & 3.32 & 7.55 & 5.00 & 4.79 & 3.56 & 2.47 & 2.01 \\
$\mathbf{1 1 . 3}$ & 3.23 & 3.17 & 7.54 & 4.85 & 4.68 & 3.41 & 2.34 & 1.98 \\
$\mathbf{1 2 . 6}$ & 3.33 & 3.28 & 8.07 & 5.02 & 4.46 & 3.28 & 2.25 & 1.93 \\
$\mathbf{1 3 . 8}$ & 3.31 & 3.24 & 5.14 & 3.58 & 4.44 & 2.03 & 2.22 & 1.84 \\
$\mathbf{1 5 . 1}$ & 3.34 & 3.27 & 5.17 & 3.57 & 4.30 & 3.01 & 2.20 & 1.86 \\
$\mathbf{1 6 . 2}$ & 1.84 & 1.81 & 3.02 & 2.25 & 2.93 & 2.24 & 1.53 & 1.28 \\
$\mathbf{1 8 . 4}$ & 1.74 & 1.72 & 2.12 & 1.91 & 1.99 & 1.76 & 1.50 & 1.35 \\
$\mathbf{1 9 . 2}$ & 1.72 & 1.70 & 2.10 & 1.89 & 1.92 & 1.70 & 1.44 & 1.32 \\
$\mathbf{2 0 . 2}$ & 1.65 & 1.64 & 2.04 & 1.84 & 1.92 & 1.71 & 1.45 & 1.32 \\
\hline
\end{tabular}

Table 3. Safety index values for three-storey square plan.

\begin{tabular}{ccccccccc}
\hline \% & A & B & C & D & E & F & G & H \\
\hline $\mathbf{8 . 3}$ & 1.59 & 1.47 & 2.66 & 2.12 & 1.98 & 1.63 & 1.42 & 1.98 \\
$\mathbf{9 . 8}$ & 1.29 & 1.18 & 1.76 & 1.55 & 1.56 & 1.35 & 1.28 & 1.56 \\
$\mathbf{1 1 . 5}$ & 1.22 & 1.10 & 1.66 & 1.46 & 1.40 & 1.24 & 1.04 & 1.40 \\
$\mathbf{1 2 . 5}$ & 1.24 & 1.13 & 1.72 & 1.50 & 1.40 & 1.24 & 1.04 & 1.40 \\
$\mathbf{1 4 . 0}$ & 1.68 & 1.51 & 2.21 & 1.95 & 1.84 & 1.65 & 1.40 & 1.84 \\
$\mathbf{1 5 . 3}$ & 1.69 & 1.51 & 2.23 & 1.96 & 1.87 & 1.67 & 1.40 & 1.87 \\
$\mathbf{1 7 . 0}$ & 1.45 & 1.27 & 1.78 & 1.65 & 1.76 & 1.57 & 0.88 & 1.76 \\
$\mathbf{1 8 . 2}$ & 1.00 & 0.91 & 1.69 & 1.53 & 1.57 & 1.12 & 0.98 & 1.57 \\
$\mathbf{1 9 . 5}$ & 1.05 & 0.97 & 1.31 & 1.22 & 1.92 & 1.71 & 1.45 & 1.32 \\
\hline
\end{tabular}

Table 4. Safety index values for two-storey rectangular plan.

\begin{tabular}{ccccccccc}
\hline \% & A & B & C & D & E & F & G & H \\
\hline $\mathbf{9 . 0}$ & 2.69 & 2.19 & 5.18 & 3.89 & 3.50 & 2.71 & 2.01 & 1.78 \\
$\mathbf{1 0 . 1}$ & 2.52 & 2.02 & 4.95 & 3.65 & 3.30 & 2.53 & 1.92 & 1.72 \\
$\mathbf{1 1 . 8}$ & 2.55 & 2.05 & 5.34 & 3.86 & 3.21 & 2.46 & 1.87 & 1.69 \\
$\mathbf{1 3 . 2}$ & 2.53 & 1.95 & 4.39 & 3.19 & 3.20 & 2.30 & 1.91 & 1.67 \\
$\mathbf{1 4 . 3}$ & 2.54 & 1.97 & 4.33 & 3.15 & 3.17 & 2.29 & 1.92 & 1.68 \\
$\mathbf{1 5 . 5}$ & 2.36 & 1.84 & 3.97 & 2.92 & 2.39 & 1.64 & 1.19 & 1.09 \\
$\mathbf{1 7 . 1}$ & 1.42 & 1.25 & 2.25 & 1.97 & 1.84 & 1.41 & 1.43 & 1.31 \\
$\mathbf{1 8 . 7}$ & 1.69 & 1.53 & 2.15 & 1.97 & 1.87 & 1.65 & 1.41 & 1.29 \\
$\mathbf{2 0 . 0}$ & 1.65 & 1.49 & 2.08 & 1.88 & 1.85 & 1.65 & 1.42 & 1.30 \\
\hline
\end{tabular}

Table 5. Safety index values for three-storey rectangular plan.

\begin{tabular}{ccccccccc}
\hline \% & A & B & C & D & E & F & G & H \\
\hline $\mathbf{8 . 3}$ & 1.38 & 1.28 & 1.68 & 1.49 & 1.56 & 1.39 & 1.22 & 1.12 \\
$\mathbf{1 0 . 1}$ & 1.27 & 1.16 & 1.75 & 1.58 & 1.44 & 1.30 & 1.12 & 1.03 \\
$\mathbf{1 1 . 4}$ & 1.08 & 0.98 & 1.40 & 1.27 & 1.22 & 1.08 & 0.95 & 0.87 \\
$\mathbf{1 2 . 3}$ & 1.07 & 0.98 & 1.41 & 1.26 & 1.20 & 1.08 & 0.95 & 0.87 \\
$\mathbf{1 4 . 0}$ & 1.46 & 1.33 & 1.86 & 1.68 & 1.66 & 1.49 & 1.27 & 1.16 \\
$\mathbf{1 5 . 5}$ & 1.43 & 1.30 & 1.81 & 1.64 & 1.60 & 1.44 & 1.24 & 1.14 \\
$\mathbf{1 6 . 8}$ & 0.93 & 0.82 & 1.50 & 1.39 & 1.43 & 0.99 & 0.75 & 0.70 \\
$\mathbf{1 8 . 1}$ & 1.03 & 0.95 & 1.28 & 1.18 & 1.19 & 1.09 & 0.91 & 0.84 \\
$\mathbf{1 9 . 3}$ & 1.01 & 0.93 & 1.26 & 1.16 & 1.15 & 1.04 & 0.89 & 0.83 \\
\hline
\end{tabular}

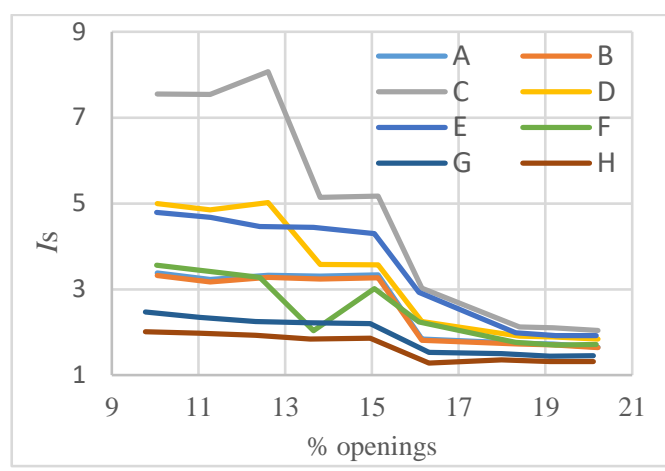

Figure 13. Square Plan - two-storey: $I_{s}$ vs. \% openings.

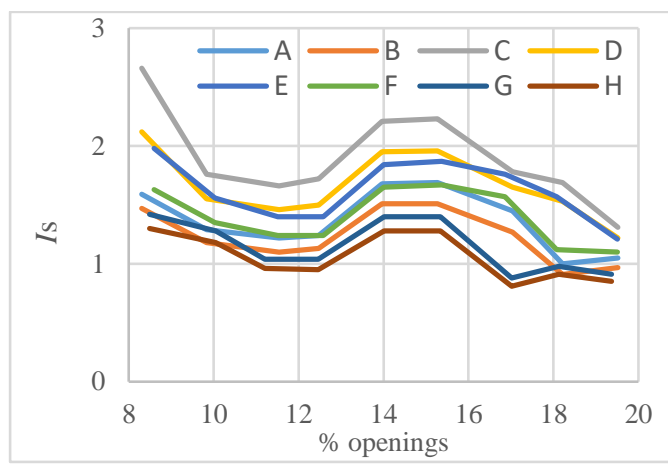

Figure 14. Square Plan - three-storey: $I_{\mathrm{s}}$ vs. \% openings.

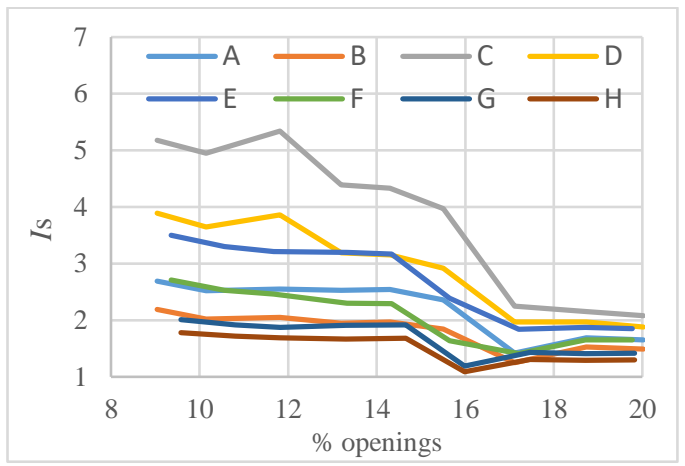

Figure 15. Rectangular Plan - two-storey: $I_{\mathrm{s}}$ vs. \% openings.

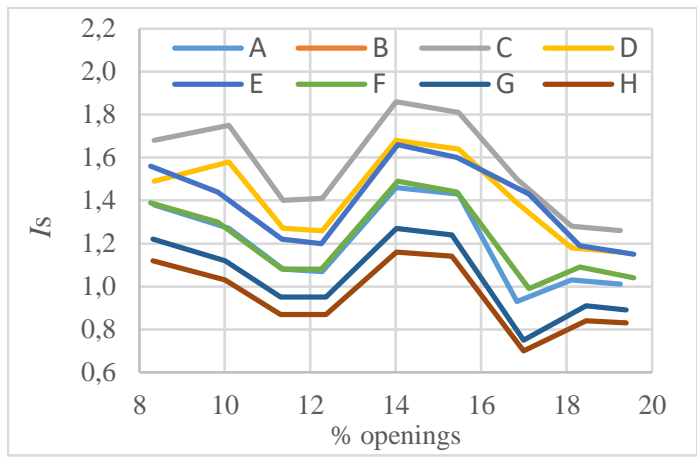

Figure 16. Rectangular Plan - three-storey: $I_{s}$ vs. \% openings. 
Table 6. Safety index values for two-storey irregular plan.

\begin{tabular}{ccccccccc}
\hline \% & A & B & C & D & E & F & G & H \\
\hline $\mathbf{7 . 2}$ & 2.39 & 2.02 & 3.92 & 3.21 & 3.67 & 3.00 & 1.67 & 1.57 \\
$\mathbf{9 . 1}$ & 2.20 & 1.86 & 3.49 & 2.86 & 3.36 & 2.75 & 1.58 & 1.47 \\
$\mathbf{1 0 . 1}$ & 2.18 & 1.83 & 3.45 & 2.83 & 3.23 & 2.69 & 1.59 & 1.47 \\
$\mathbf{1 1 . 5}$ & 2.23 & 1.83 & 3.65 & 2.90 & 3.45 & 2.75 & 1.53 & 1.41 \\
$\mathbf{1 3 . 0}$ & 2.34 & 1.87 & 3.86 & 2.69 & 2.78 & 2.30 & 1.57 & 1.45 \\
$\mathbf{1 4 . 2}$ & 2.00 & 1.72 & 3.14 & 2.55 & 2.70 & 2.23 & 1.50 & 1.40 \\
$\mathbf{1 5 . 4}$ & 1.52 & 1.39 & 2.00 & 1.70 & 1.77 & 1.57 & 1.27 & 1.19 \\
$\mathbf{1 7 . 3}$ & 1.47 & 1.34 & 1.87 & 1.64 & 1.74 & 1.53 & 1.26 & 1.17 \\
$\mathbf{1 9 . 0}$ & 1.46 & 1.35 & 1.86 & 1.63 & 1.75 & 1.54 & 1.24 & 1.17 \\
\hline
\end{tabular}

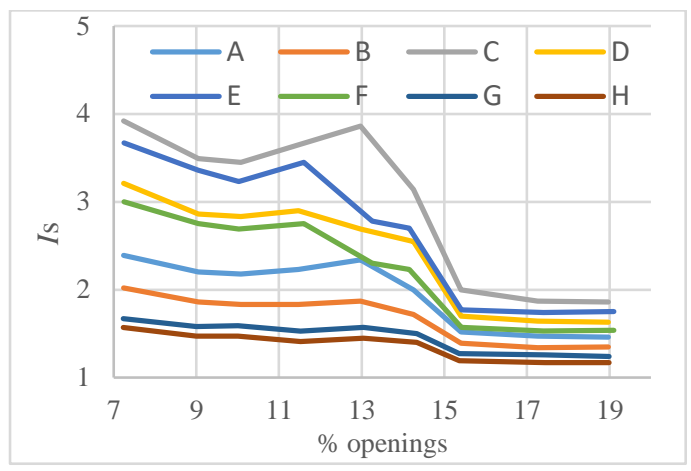

Figure 17. Irregular Plan - two-storey: $I_{s}$ vs. \% openings.

Table 7. Safety index values for two-storey irregular plan.

\begin{tabular}{ccccccccc}
\hline \% & A & B & C & D & E & F & G & H \\
\hline $\mathbf{8 . 1}$ & 1.25 & 1.15 & 1.59 & 1.47 & 1.40 & 1.28 & 1.15 & 1.11 \\
$\mathbf{9 . 3}$ & 1.45 & 1.09 & 1.49 & 1.37 & 1.37 & 1.25 & 1.04 & 0.99 \\
$\mathbf{1 0 . 1}$ & 1.18 & 1.07 & 1.47 & 1.37 & 1.30 & 1.19 & 1.08 & 0.99 \\
$\mathbf{1 1 . 4}$ & 1.14 & 1.03 & 1.37 & 1.30 & 1.24 & 1.14 & 0.93 & 1.00 \\
$\mathbf{1 3 . 1}$ & 1.11 & 1.00 & 1.33 & 1.25 & 1.18 & 1.09 & 1.07 & 0.96 \\
$\mathbf{1 4 . 0}$ & 1.12 & 1.01 & 1.33 & 1.26 & 1.20 & 1.10 & 1.02 & 0.95 \\
$\mathbf{1 5 . 4}$ & 1.09 & 0.98 & 1.32 & 1.22 & 1.21 & 1.11 & 0.95 & 0.88 \\
$\mathbf{1 7 . 0}$ & 1.02 & 0.95 & 1.23 & 1.17 & 1.15 & 1.09 & 1.21 & 1.13 \\
$\mathbf{1 8 . 4}$ & 1.00 & 0.94 & 1.19 & 1.14 & 1.11 & 1.05 & 0.59 & 0.56 \\
\hline
\end{tabular}

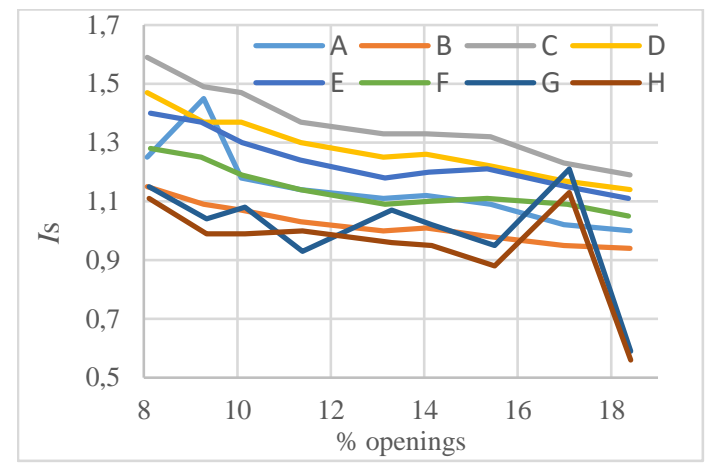

Figure 18. Irregular Plan - two-storey: $I_{s}$ vs. \% openings.

\subsection{Physical part}

A possible solution to the SHM physical part [67] involves a wired sensor network characterised by two types of piezoelectric accelerometer sensor (Integrated Electronic PiezoelectricIEPE): a KS48C-MMF with a voltage sensitivity of $1 \mathrm{~V} / \mathrm{g}$ and a measurement range of $\pm 6 \mathrm{~g}$, and a KB12VD-MMF with a voltage sensitivity of $10 \mathrm{~V} / \mathrm{g}$ and a measurement range of \pm 0.6 g. The data recorded with the sensors are acquired via a gateway to be sent to a remote control and service room [68], [69], where they will be analysed and compared to the results obtained via the finite elements model (FEM) in order to obtain the value of the control point displacement $\left(u_{\max }\right)$.

\subsection{Cyber part}

Nowadays, natural computing is employed to automate the monitoring processes so as to reduce human error. Here, the possible sources of error are identified via a sensitivity analysis of the parameters used in the dynamic models. Meanwhile, natureinspired algorithms are adopted to ensure convergent solutions to the problems in a local context, with specific attention paid to the suitability of the solutions to constraints problems, such as optimal sensor placement (OSP) and model-based damage identification (DI). Specifically, when the DI strategies are used, it is possible to assess specific damage parameters from alterations in the elastic-mechanical properties of the structural system by solving the inverse problem of the system analysed [70]-[73].

Vibration-based methods allow for the initial individuation of damage by means of dynamic property measurements. These methods relate to the changes in the mass, damping, and rigidity of the system, determined through the analysis of natural frequencies using accelerometers [74]-[75].

\section{CONCLUSIONS}

The pushover analyses conducted in relation to various configurations of two- and three-storey BTs returned some important results. First, the safety index always demonstrated values more significant than 1 in the case of two-storey buildings, while the reliability condition was rarely not satisfied with the three-storey buildings. An index reduction was also noted with the buildings with a regular plan compared to those with an irregular plan. As could be expected, the performance decay was due to the weaker mechanical properties of the calculation model, such as the type of masonry and the flexural strength of the floors. The increase in the storey height, as well as the percentage of openings in the main façade, led to adverse effects on the seismic safety. However, the index tended toward analogous values regardless of the structural properties of the model.

Specifically, the vulnerability elements were ordered as follows: the number of floors $\rightarrow$ the storey height $\rightarrow$ the stiffness of the slabs $\rightarrow$ the percentage of openings (with a focus on their vertical misalignment) $\rightarrow$ the plan shape. This is shown in Figure 19-Figure 22, where all configurations characterised by a non-verified safety index Is are presented, the analysis of which led to defining the scale of possible vulnerability. Therefore, the proposed SHM system could be applied to buildings that present the above-defined elements according to the vulnerability ranking (Figure 23). The identification of the buildings most exposed to seismic risk using the CARTIS approach will lead to 


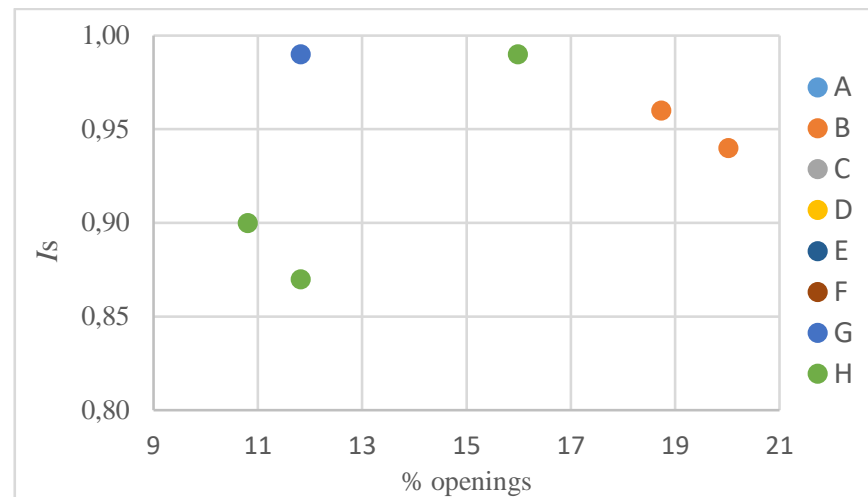

Figure 19. Distribution of non-verified Is for two-storey rectangular plan model for each seismic load distribution.

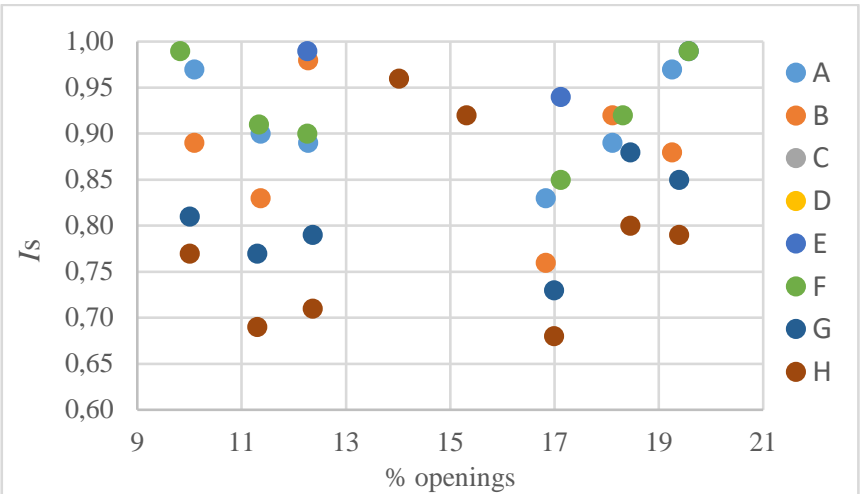

Figure 20. Distribution of non-verified Is for three-storey rectangular plan model for each seismic load distribution.

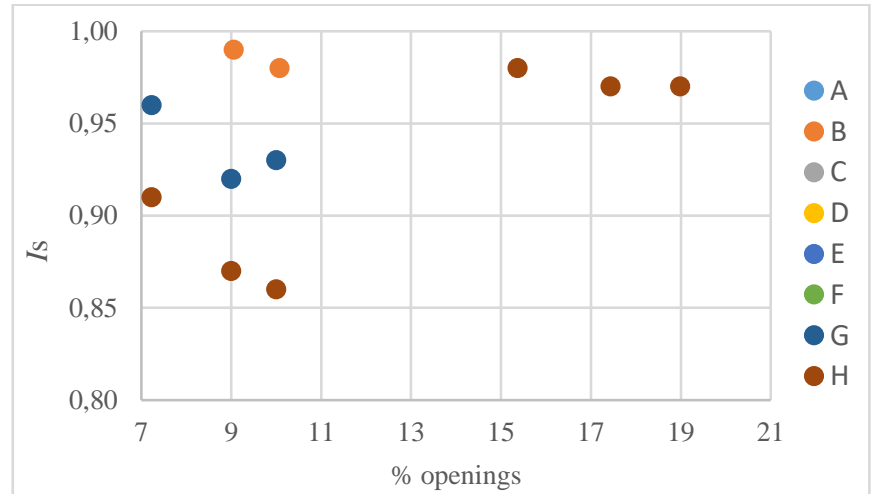

Figure 21. Distribution of non-verified Is for two-storey irregular plan model for each seismic load distribution.

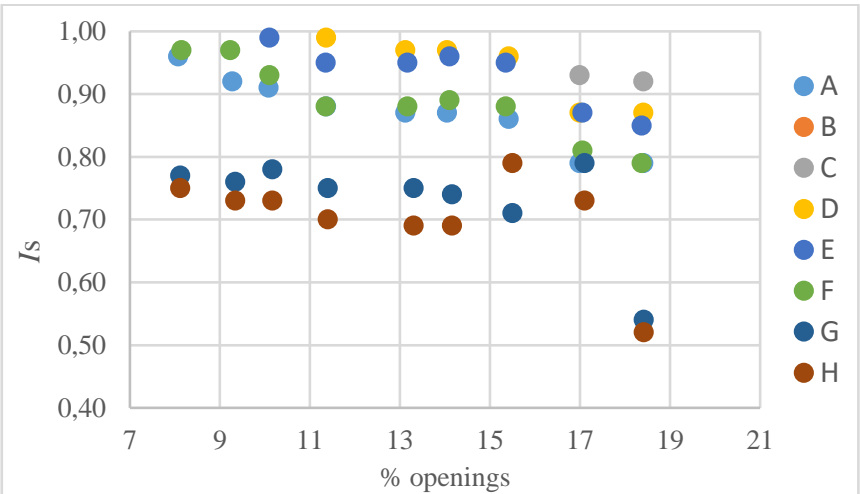

Figure 22. Distribution of non-verified Is for three-storey irregular plan model for each seismic load distribution.

\begin{tabular}{|l|l|}
\hline & Number of floors \\
\hline & Average storey height \\
\hline & Slab stiffness \\
\hline & $\%$ openings \\
\hline & Plan shape \\
\hline & Masonry properties \\
\hline
\end{tabular}

Figure 23. Vulnerability ranking of various structural elements.

a reduction in both costs and computational burden. The buildings identified would be monitored via SHM after calculating the maximum displacement demand $\left(d_{\max }\right)$ for each. The dynamic solicitations recorded by the system would subsequently be sent in real time to a control room in order to identify whether the $I s$ is less than or greater than the unit, carrying out a highly accurate analysis via FEM.

\section{REFERENCES}

[1] A. Ferrante, F. Clementi, G. Milani, Advanced numerical analyses by the non-smooth contact dynamics method of an ancient masonry bell tower, Mathematical Methods in the Applied Sciences, 43 (13), 2020, pp.7706-7725.

DOI: $\underline{10.1002 / \mathrm{mma} .6113}$

[2] F. Clementi, G. Milani, A. Ferrante, M. Valente, S. Lenci, Crumbling of Amatrice clock tower during 2016 central Italy seismic sequence: Advanced numerical insights, Frattura ed Integrità Strutturale, 14(51) (2020), pp. 313-335.

DOI: $10.3221 /$ IGF-ESIS.51.24

[3] V. Nastro, D. L. Carnì, A. Vitale, F. Lamonaca, M. Vasile, Passive and active methods for radon pollution measurements, Historical Heritage Buildings, Measurement 114 (2018), pp. 526-533. DOI: $10.1016 /$ i.measurement.2016.09.002

[4] G. Standoli, E. Giordano, G. Milani, F. Clementi, Model updating of historical belfries based on OMA identification techniques, International Journal of Architectural Heritage 14 (2020), pp. 125.

DOI: $\underline{10.1080 / 15583058.2020 .1723735}$

[5] F. Ubertini, G. Comanducci, N. Cavalagli, A. L. Pisello, A. L. Materazzi, F. Cotana, Environmental effects on natural frequencies of the San Pietro Bell Tower in Perugia, Italy, and their removal for structural performance assessment, Mechanical Systems and Signal Processing 82 (2017), pp. 307-322. DOI: $\underline{10.1016 / \text { i.ymssp.2016.05.025 }}$

[6] M. Polese, M. Gaetani d'Aragona, A. Prota, Simplified approach for building inventory and seismic damage assessment at the territorial scale: An application for a town in southern Italy, Soil Dynamics and Earthquake Engineering 121 (2019), pp. 405-420. DOI: 10.1016/i.soildyn.2019.03.028

[7] F. Lamonaca, et al., Internet of things for structural health monitoring, 2018 Workshop on Metrology for Industry 4.0 and IoT, Brescia, Italy, 2018, pp. 95-100.

DOI: $10.1109 /$ METROI4.2018.8439038

[8] F. Lamonaca, P. F Sciammarella, C. Scuro, D.L. Carnì, R. S. Olivito, Monitoring of environmental parameters and pollution by fungal spores in the National Gallery of Cosenza: a case study, Measurement 47 (2014), pp.1001-1007.

DOI: $10.1016 /$ i.measurement.2013.09.014

[9] P. Daponte, F. Lamonaca, F. Picariello, L. De Vito, G. Mazzilli, I. Tudosa, A survey of measurement applications based on IoT, Proc. of IEEE International Workshop on Metrology for Industry 4.0 and IoT, Brescia, Italy, 16 - 18 April, 2018, pp. 1-6. DOI: $10.1109 /$ METROI4.2018.8428335

[10] E. Balestrieri, L. De Vito, F. Lamonaca, F. Picariello, S. Rapuano, I. Tudosa, Research challenges in measurements for Internet of Things systems, ACTA IMEKO 7(4) (2018), pp. 82-94. DOI: $10.21014 /$ acta imeko.v7i4.675 
[11] C. Scuro, P.F. Sciammarella, F. Lamonaca, R.s.Olivito, D. L. Carni, IoT for structural health monitoring, IEEE Instrumentation and Measurement Magazine 21(6) (2018), pp. 4 14. DOI: 10.1109/MIM.2018.8573586

[12] F. Lamonaca, D. L. Carnì, M. Riccio, D. Grimaldi, G. Andria, Preserving synchronization accuracy from the plug-in of nonsynchronized nodes in a wireless sensor network, IEEE Transactions on Instrumentation and Measurement 66 (2017), pp. 1058-1066.

DOI: 10.1109/TIM.2017.2664422

[13] A. Barontini, M. G. Masciotta, L. F. Ramos, P. Amado-Mendes, P. B. Lourenço, An overview of nature-inspired optimization algorithms for structural health monitoring of historical buildings, Procedia Engineering 199 (2017), pp. 3320-3325. DOI: $10.1016 /$ i.proeng.2017.09.439

[14] C. R. Farrar, K. Worden, An introduction to structural health monitoring, Philosophical Transactions of the Royal Society of London A: Mathematical, Physical and Engineering Sciences 365 (2007), pp. 303-315 DOI: $10.1007 / 978-3-7091-0399-91$

[15] R. S. Olivito, S. Porzio, C. Scuro, D. L. Carnì, F. Lamonaca, SHM systems applied to the built heritage inventory at the territorial scale. A preliminary study based on the CARTIS approach. IMEKO TC4 International Conference on Metrology for Archaeology and Cultural Heritage, Florence, Italy, 4-6 December 2019, pp. 53-58. Online [Accessed 19 March 2021]

https://www.imeko.org/publications/tc4-Archaeo2019/IMEKO-TC4-METROARCHAEO-2019-10.pdf

[16] I. Ngoma, I. Kafodya, P. Kloukinas, V. Novelli, J. Macdonald, K. Goda, Building classification and seismic vulnerability of current housing construction in Malawi, Malawi Journal of Science and Technology 11(1) (2019), pp. 57-72. Online [Accessed 19 March 2021]

https://www.ajol.info/index.php/mjst/article/view/185783

[17] R. Vicente, S. Parodi, S. Lagomarsino, H. Varum, J. M. Silva, Seismic vulnerability and risk assessment: case study of the historic city centre of Coimbra, Portugal. Bulletin of Earthquake Engineering 9(4) (2011), pp. 1067-1096. DOI: $10.1007 / \mathrm{s} 10518-010-9233-3$

[18] A. Yakut, G. Ozcebe, M. S. Yucemen, Seismic vulnerability assessment using regional empirical data, Earthquake Engineering \& Structural Dynamics 35(10) (2006), pp. 1187-1202.

DOI: $10.1002 /$ eqe. 572

[19] G. M. Calvi, R. Pinho, G. Magenes, J. J. Bommer, L. F. RestrepoVélez, H. Crowley, Development of seismic vulnerability assessment methodologies over the past 30 years, ISET Journal of Earthquake Technology 43(3) (2006), pp. 75-104.

[20] M. Dolce, A. Kappos, A. Masi, G. Penelis, M. Vona, Vulnerability assessment and earthquake damage scenarios of the building stock of Potenza (Southern Italy) using Italian and Greek methodologies, Engineering Structures 28(3) (2006), pp. 357-371. DOI: $10.1016 /$ i.engstruct.2005.08.009

[21] S. Cattari, S. Lagomarsino, D. Ottonelli, Fragility curves for masonry buildings from empirical and analytical models, Proc. of 2nd European Conference on Earthquake Engineering and Seismology, Istanbul, Turkey, 25 - 29 August, 2014, pp. 25-29.

[22] A. K. Eleftheriadou, A. I. Karabinis, Damage probability matrices derived from earthquake statistical data, Proceedings of the 14th World Conference on Earthquake Engineering, Beijing, China, 2008, pp. 07-0201.

[23] G. Zuccaro, F. Dato, F. Cacace, D. De Gregorio, S. Sessa, Seismic collapse mechanisms analyses and masonry structures typologies: a possible correlation, International Journal of Earthquake Engineering 4 (2017), pp. 121-149.

[24] E. Choi, R. DesRoches, B. Nielson, Seismic fragility of typical bridges in moderate seismic zones, Engineering Structures 26(2) (2004), pp. 187-199.

DOI: $10.1016 /$ i.engstruct.2003.09.006
[25] P. Lonetti, A. Pascuzzo, Vulnerability and failure analysis of hybrid cable-stayed suspension bridges subjected to damage mechanisms, Engineering Failure Analysis 45 (2014), pp. 470-495.

DOI: $10.1016 /$ i.engfailanal.2014.07.002

[26] B. G. Nielson, R. DesRoches, R., Seismic fragility methodology for highway bridges using a component level approach, Earthquake Engineering \& Structural Dynamics 36(6) (2007), pp. 823-839.

DOI: $10.1002 /$ eqe. 655

[27] B. G. Nielson, R. DesRoches, Seismic fragility methodology for highway bridges, Structures Congress 2006: Structural Engineering and Public Safety, 2006, pp. 1-9.

DOI: $10.1061 / 40889(201) 174$

[28] R. P. Kennedy, M. K. Ravindra, Seismic fragilities for nuclear power plant risk studies, Nuclear Engineering and Design 79 (1984), pp. 47-68. DOI: $\frac{10.1016 / 0029-5493(84) 90188-2}{2.10}$

[29] Z. Cai, W. C. Xie, M. D. Pandey, S. Ni, Determining seismic fragility of structures and components in nuclear power plants using multiple ground motion parameters - Part II: Application, Nuclear Engineering and Design; v. 335 (2018), pp. 186-194 DOI: $10.1016 /$ i.nucengdes.2018.05.016

[30] Z. Cai, Seismic Fragility Analysis for Structures, Systems, and Components in Nuclear Power Plants, University of Waterloo, 2017.

http://hdl.handle.net/10012/11205

[31] I. Caliò, B. Pantò, A macro-element modelling approach of infilled frame structures, Computers and Structures 143 (2014), pp. 91107. DOI: $10.1016 /$ i.compstruc. 2014.07 .008

[32] A. Formisano, N. Chieffo, M. Mosoarca, Seismic vulnerability and damage speedy estimation of an urban sector within the municipality of San Potito Sannitico (Caserta, Italy), The Open Civil Engineering Journal. Vol.11(1) (2017), pp1106-1121. DOI: 10.2174/1874149501711011106

[33] G. Milani, A. Formisano, F. Clementi, Numerical modeling, experimentation and design practice for masonry structures in seismic prone areas, AIP Conference Proceedings 1906(1) (2017), p. 090001. DOI: $10.1063 / 1.5012358$

[34] R. S. Olivito, R. Codispoti, C. Scuro, A seismic analysis for masonry constructions: The different schematization methods of masonry walls, AIP Conference Proceedings 1906(1) (2017), p. 090007. DOI: $\underline{10.1063 / 1.5012364}$

[35] S. Lagomarsino, A. Penna, A. Galasco, S. Cattari, TREMURI program: An equivalent frame model for the nonlinear seismic analysis of masonry buildings, Engineering Structures 56 (2013), pp. 1787-1799. DOI: $10.1016 /$ i.engstruct.2013.08.002

[36] R. S. Olivito, C. Scuro, R. Codispoti, S. Porzio, A seismic analysis for ancient Trentacapilli palace with different schematization methods of masonry walls, Proceedings of the International Masonry Society Conferences, Milan, Italy, 9-11 July 2018, pp. 2555-2562.

[37] F. Greco, P. Lonetti, A. Pascuzzo, A moving mesh FE methodology for vehicle-bridge interaction modelling, Mechanics of Advanced Materials and Structures 27(14) (2020), pp. 12561268. DOI: $10.1080 / 15376494.2018 .1506955$

[38] P. Lonetti, A. Pascuzzo, A numerical study on the structural integrity of self-anchored cable-stayed suspension bridges. Frattura ed Integrità Strutturale 10(38) (2016), pp. 358-376. DOI: $10.3221 /$ IGF-ESIS.38.46

[39] P. Lonetti, A. Pascuzzo, S. Aiello, Instability design analysis in tiedarch bridges, Mechanics of Advanced Materials and Structures 26(8) (2019), pp. 716-726. DOI: $10.1080 / 15376494.2017 .1410911$

[40] C. Scuro, S. Tiverti, R. Codispoti, G. Milani, R.S. Olivito, Fictile tubules: A traditional Mediterranean construction technique for 
masonry vaulted systems, Construction and Building Materials 193 (2018), pp. 84-96.

DOI: $10.1016 /$ i.conbuildmat.2018.10.156

[41] C. Scuro, F. Lamonaca, R. Codispoti, D. L. Carnì, R. S. Olivito, Experimental and numerical analysis on masonry arch built with fictile tubules bricks, Measurement 130 (2018), pp. 246-254. DOI: $10.1016 /$ i.measurement.2018.08.001

[42] F. Clementi, E. Quagliarini, F. Monni, E. Giordano, S. Lenci, Cultural heritage and earthquake: The case study of 'Santa Maria della Carità' in Ascoli Piceno, The Open Civil Engineering Journal, Vol. 11(1), (2017), pp.1079-1105. DOI: $10.2174 / 1874149501711011079$

[43] S. Cattari, S. Lagomarsino, A strength criterion for the flexural behavior of spandrels in un-reinforced masonry walls, The $14^{\text {th }}$ World Conference on Earthquake Engineering, Beijing, China, 2008.

[44] I. Caliò, M. Marletta, B. Pantò, A new discrete element model for the evaluation of the seismic behaviour of unreinforced masonry buildings, Engineering Structures 40 (2012), pp. 327-38. DOI: $10.1016 /$ i.engstruct.2012.02.039

[45] P. Lonetti, A. Pascuzzo, A practical method for the elastic buckling design of network arch bridges, International Journal of Steel Structures 20(6) (2019), pp. 311-329.

DOI: $10.1007 /$ s13296-019-00282-8

[46] G. Milani, K. Beyer, A. Dazio, Upper bound limit analysis of meso-mechanical spandrel models for the pushover analysis of $2 \mathrm{D}$ masonry frames, Engineering Structures 31(11) (2009), pp. 26962710 .

DOI: $10.1016 /$ i.engstruct.2009.06.015

[47] A. Cundari, G. Milani, Homogenized and heterogeneous limit analysis model for the pushover analysis of ancient masonry walls with irregular texture, International Journal of Architectural Heritage 7(3) (2013), pp. 303-338. DOI: $10.1080 / 15583058.2011 .640737$

[48] R. S. Olivito, C. Scuro, S. Porzio, R. Codispoti, F. Demarco, Seismic vulnerability of ancient masonry buildings: the case study of low-rise towers, AIP Conference Proceedings 2116 (1) (2019), p. 420007.

DOI: $10.1063 / 1.5114434$

[49] F. Ubertini, G. Comanducci, N. Cavalagli, Vibration-based structural health monitoring of a historic bell-tower using outputonly measurements and multivariate statistical analysis, Structural Health Monitoring 15(4) (2016), pp.438-457.

DOI: $10.1177 / 1475921716643948$

[50] X.-H. Zhang, Y.-L. Xu, S. Zhu, S. Zhan, Dual-type sensor placement for multi-scale response reconstruction, Mechatronics 24(4) (2014), pp. 376-384

[51] C. Scuro, F. Lamonaca, D. L. Carnì, R. S. Olivito, G. Milani, An innovative structural health monitoring system for the preliminary study of an ancient anti-seismic construction technique, IMEKO TC4 International Conference on Metrology for Archaeology and Cultural Heritage, Florence, Italy, 4-6 December 2019, pp. 43-47. Online [Accessed 19 March 2021]

https://www.imeko.org/publications/tc4-Archaeo2019/IMEKO-TC4-METROARCHAEO-2019-8.pdf

[52] X.-H. Zhang, Y.-L. Xu, S. Zhu, S. Zhan, Dual-type sensor placement for multi-scale response reconstruction, Mechatronics 24(4) (2014), pp. 376-384

DOI: $10.1016 /$ i.mechatronics.2013.05.007

[53] A. Pierdicca, F. Cleminti, D. Isidori, E. Concettoni, C. Cristalli, S Lenci, Numerical model upgrading of a historical masonry palace monitored with a wireless sensor network, International Journal of Masonry Research and Innovation 1(1) (2016), pp. 74-98. DOI: $10.1504 /$ IJMRI.2016.074748

[54] J. Gubbi, R. Buyya, S. Marusic, M. Palaniswami, Internet of Things (IoT): A vision, architectural elements, and future directions, Future Generation Computer Systems 29(7) (2013), pp. 16451660.

DOI: $10.1016 /$ j.future.2013.01.010
[55] R. Kitchin, Big Data, new epistemologies and paradigm shifts, Big Data \& Society . Vol. 1(1) (2014), pp. 1-12. DOI: $10.1177 / 2053951714528481$

[56] R. S. Olivito, S. Porzio, A new multi-control-point pushover methodology for the seismic assessment of historic masonry buildings, Journal of Building Engineering Vol.26, (2019), pp.1-15. DOI: $10.1016 /$ j.jobe.2019.100926

[57] F. Lamonaca, A. Carrozzini, D. Grimaldi, R.S. Olivito, Improved monitoring of acoustic emissions in concrete structures by multitriggering and adaptive acquisition time interval, Measurement. 59 (2015), pp. 227-236

DOI: $10.1016 /$ i.measurement.2014.09.05.

[58] F. Lamonaca, A. Carrozzini, D. Grimaldi, R. S. Olivito, Acoustic emission monitoring of damage concrete structures by multitriggered acquisition system, Proc. of I2MTC 2012-IEEE International Instrumentation and Measurement Technology Conference, Graz, Austria, 13 - 16 May, 2012, pp. 1630-1634. DOI: $10.1109 /$ I2MTC.2012.6229657

[59] R. Olivito, S. Porzio, M. F. Funari, C. Scuro, F. Demarco, A numerical-geometrical methodology to represent out of-plane mechanisms of unreinforced masonry structures by using pushover analysis, COMPDYN 2019 VII Conference of Computational Methods in Structural Dynamic and Earthquake Engineering, Crete, Greece, 24 - 26 June, 2019, pp. 24-26. DOI: $10.7712 / 120119.6995 .18840$

[60] R. S. Olivito, S. Porzio, A. Tedesco, An interdisciplinary approach for the seismic vulnerability assessment of historic masonry buildings: the case study of the Ex Jesuits College in Amantea (Italy), in: Structural Analysis of Historical Constructions, Springer, Cham., 2019, pp. 1247-1256. ISBN: 978-3-319-99440-6.

[61] R. S. Olivito, S. Porzio, C. Scuro, R. Codispoti, Evaluations on the seismic vulnerability of masonry churches: A case study in Amantea (Cosenza-Italy), AIP Conference Proceedings 2040(1) (2018), p. 090009.

DOI: $10.1063 / 1.5079155$

[62] S. Tiberti, C. Scuro, R. Codispoti, R. S. Olivito, G. Milani, Experimental and numerical analysis of historical aseismic construction system, in: Structural Analysis of Historical Constructions, Springer, Cham., 2019, pp. 910-918. DOI: $10.1007 / 978-3-319-99441-3 \quad 98$

[63] F. Clementi, P.A. Mezzapelle, G. Cocchi, S. Lenci, Global analyses of historical masonry buildings: Equivalent frame vs. 3D solid models, AIP Conference Proceedings (2017), Vol. 1863, No. 1, p. 450006.

DOI: $10.1063 / 1.4992615$

[64] F. Lamonaca, R. S. Olivito, S. Porzio, D. L. Carnì, C. Scuro, Structural health monitoring system for masonry historical construction, Proc. of International Conference on Metrology for Archaeology and Cultural Heritage METROARCHAEO 2018, Cassino, Italy, 22-24 October 2018. DOI: $10.1109 /$ MetroArchaeo43810.2018.9089776

[65] MIT, Italian Technical Standard. NTC 2018 - Update of technical standards for construction. Official Gazette of the Italian Republic, 2018, series 42. (WI-GU-2018-SON-005) (in Italian).

[66] MIT Italian Technical Standard. NTC 2018. Document 2 feb. 2009, n. 617, Instructions for the application of the "New technical standards for construction". 2009. (In Italian).

[67] D. L. Carni, D. Grimnaldi, F. Lamonaca, L. Nigro, P. F. Sciammarella, From distributed measurement systems to cyberphysical systems: A design approach, International Journal of Computing 16 (2017), pp. 66-73. DOI: $10.47839 /$ ijc. 16.2 .882

[68] F. Lamonaca, P.F. Sciammarella, C. Scuro, D.L. Carnì, R.S. Olivito, Synchronization of IoT layers for structural health monitoring, 2018 Workshop on Metrology for Industry 4.0 and IoT, Brescia, Italy, April, 2018, pp. 89-94. DOI: $10.1109 /$ METROI4.2018.8428329

[69] F. Lamonaca, C. Scuro, D. Grimaldi, R.S. Olivito, P.F. Sciammarella, D.L. Carnì, A layered IoT-based architecture for a distributed structural health monitoring system, Acta Imeko 8(2) 
(2019), pp 45-42.

DOI: http://dx.doi.org/10.21014/acta imeko.v8i2.640

[70] A. Barontini, M. Masciotta, L. Ramos, P. Mendes, P. Lourenco, An overview on nature-inspired optimization algorithms for structural health monitoring of historical buildings, Procedia Engineering 199 (2017), pp. 3320-3325.

DOI: $10.1016 /$ i.proeng.2017.09.439

[71] A. Formisano, G. Di Lorenzo, L. Krstevska, R. Landolfo, FEM model calibration of experimental environmental vibration tests on two churches hit by L'Aquila Earthquake, International Journal of Architectural Heritage 7 (2020), pp. 1-19. DOI: $10.1080 / 15583058.2020 .1719233$

[72] A. Formisano, L. Krstevska, G. Di Lorenzo, R. Landolfo Ambient vibration test and numerical investigation on the St. Giuliano church in Poggio Picenze (L'aquila, Italy), Journal of
Civil Structural Health Monitoring 9(4) (2019), pp. 477-490. DOI: $10.1007 / \mathrm{s} 13349-019-00346-7$

[73] A. Formisano, L. Krstevska, G. Di Lorenzo, R. Landolfo. Experimental ambient vibration tests and numerical investigation on the Sidoni Palace in Castelnuovo of San Pio (L'Aquila, Italy), Int. J. Masonry Research and Innovation 3(3) (2018), pp. 269. DOI: 10.1504/IJMRI.2018.093487

[74] A. Serov, Cognitive sensor technology for structural health monitoring, Procedia Structural Integrity 5 (2017), pp. 1160-1167. DOI: $10.1016 / \mathrm{j} \cdot$ prostr.2017.07.027

[75] L. Marcheggiani, F. Clementi, A. Formisano. Static and dynamic testing of highway bridges: a best practice example, Journal of Civil Structural Health Monitoring 10(1) (2020), pp. 28-39. DOI: $10.1007 / \mathrm{s} 13349-019-00368-1$ 